\title{
De-Centering and Recentering Digital Scholarship: A Manifesto
}

Co-authored by the Office of Digital Research and Scholarship at Florida State University

Carolyn Moritz, Rachel Smart, Aaron Retteen, Matthew Hunter, Sarah Stanley, Devin Soper, Micah Vandegrift*

$\left({ }^{*}\right.$ Corresponding author - mvandegrift@fsu.edu)

\section{Introduction}

Digital Scholarship is a mode of work that is at its core collaborative, typically project-based, prone toward openness, dependent on technological infrastructure, and predisposed towards new or emerging research methods. As such, the practice of digital scholarship actively pushes back on traditional models of labor in the academy, and challenges notions of academic hierarchy, especially in research. Librarianship's core values align closely to these characteristics of equity, and digital scholarship places libraries in a central role as a transdisciplinary site of scholarly engagement. Our investment in infrastructure (human, technical, policy, workflows), and commitment to equitable and sustainable information dissemination actively bridges divides between siloed disciplines and institutions.

As digital scholarship evolves, it embraces a culture of innovation, not simply for innovation's sake but due to necessity in the face of a rapidly evolving world. Digital scholarship resists definition so thoroughly that attempts at prescribing any sort of definitive framework has been an exercise in futility. However, threads of common practice are identifiable-not in what "Digital Scholarship Is", but what in what "Digital Scholarship Does." These overlapping threads allow us to describe the interactions between technology-enhanced research and the academy, writ large.

Therefore, we choose to rethink the monolithic model of digital scholarship that seeks to define, outline, and cordon off these digital scholarly activities into discrete units, spaces, and job descriptions. A prescriptivist way of thinking about the field of digital scholarship manifests itself through frequent attempts to define "what digital scholarship is," but it also plays out in the ways that libraries develop programs and services. Too often, we focus on building "centers" for addressing campus needs related to digital scholarship. This serves to cloister digital scholarship, secluding digital work, project development, and deep thinking about sustainable labor and technology, rather than pulling these into the day-to-day efforts of the library's mission. Rather than locating digital scholarship within an administrative "center," we advocate for the "recentering" of digital scholarship and its activities as a core practice for all the intellectual and knowledge work done in libraries. 
To that end, we venture the following theses:

\section{Theses}

\section{Digital Scholarship...}

\section{1. ...redefines the norms of Promotion \& Tenure in academia}

- Insofar as digital scholarship is a highly collaborative endeavour that involves new research methods and enables radically new contributions to the scholarly record, it challenges long-standing conventions concerning the evaluation of research outputs for promotion \& tenure.

- For the digital scholarship enterprise to be successful, it will redefine these conventions, ensuring that researchers are adequately rewarded for their efforts and outputs in this arena of scholarly theory and practice.

- Digital scholarship advocates for the citation, crediting, and compensation of nontraditional work in the academy, including especially the activities outlined in the Taxonomy of Digital Research Activities in the Humanities, and the various statements about evaluating digital work from professional associations (MLA, CAA, $\underline{A H A}$.

\section{2. ... actively disrupts unsustainable infrastructure of information dissemination}

- Digital scholarship projects and outcomes challenge the notion that academic contributions are made solely through published papers/books that compete for relevance and superiority. In the "open age," we challenge the validity of continuing to uphold publishing models borne out of a print-based era. The air of conservatism in academia regarding experimentation in the delivery of ideas is in direct tension with the growing understanding that conventional units of scholarship are not always the best way to communicate an idea or concept.

- Digital scholarship creates and promotes more efficient, effective solutions for the broad dissemination of scholarship to all who might conceivably benefit from it. In turn, it is incumbent on all digital scholarship practitioners to familiarize themselves with and actively critique the prevailing infrastructures upon which their work is produced and disseminated, with a view to making more informed decisions about how and where we publish and, in time, imagine new modes of dissemination that transcend the limitations of current publishing practices.

- It is not enough to put the burden of promoting open scholarship on "functional specialists" in the library. Rather, the activities of promoting open and digitally accessible, machine-readable, and transformable scholarship should be recentered as a part of the library's mission to promote access for all. 


\section{3. ...changes the role of libraries and librarians}

- Philosophically, and often physically, libraries sit at the center of a university campus. Digital Scholarship Centers, a model for supporting new kinds of intellectual labor, have often been situated with/in the library. As "digital scholarship" has evolved from humanities-based technology projects, to include public access support, data management and curation, digital pedagogy, open educational resources, and much more, we believe the library must shed the Center-mentality to allow these and related activities to permeate the entire organization and cross boundaries with other campus research organizations.

- Library workers performing digital scholarship (whether singly or as part of other projects) are experts in areas of scholarly practice vital to the ethical and sustainable production and dissemination of scholarship in the 21st century. That is to say, library workers engaged in digital scholarly work bring scholarly expertise on topics such as openness, sustainability, innovative publication methods (etc), to the table; contributions on these topics are equally as valuable as subject or content expertise, and further scholarship as a whole immensely. As library workers performing digital scholarship continue to play more important roles in scholarly work, they are rightfully seizing increasing portions of credit in these projects. This increased level of attribution, earned through their work, positions these participants in digital scholarship as fully-vetted contributors and collaborators. As collaborators, digital scholars within the library are redefining not only attribution and power dynamics currently entrenched in academia, but reinforcing the value of library contributions as vital to modern scholarship.

\section{4. ...produces research outputs for consumption beyond the academy}

- Whereas traditionally produced scholarship largely plays into the hands of the oligopoly of academic publishers and the entrenchment of an increasingly restrictive global intellectual property regime, digital scholarship strives to disseminate the fruits of scholarly research as widely as possible. From digital special collections and projects to open access publishing and archiving to open-source software development, DS professionals are the vanguard of efforts to advance open research and teaching practices in the academy. In an age when the internet has completely revolutionized the way that we share and access information, the antiquated status quo of locking digital collections, research outputs, and educational materials behind barriers is no longer ethical or tenable.

- In addition to directly benefiting researchers, teachers, and learners, openness also supports meaningful interaction between theory and practice, creates opportunities for scholarship to influence policy and public opinion, increases the profile of the academic enterprise in the public sphere, and contributes to the development of a more informed, democratic society. Though it may be 
comforting to think that the old way of doing things will persist indefinitely, we have a professional obligation to challenge this notion and encourage teachers, learners, colleagues, and administrators to embrace a future of academic work that prioritizes equitable access and sustainable production.

\section{5. ...builds communities}

- Digital scholarship gathers diverse groups toward common goals. In contrast to the academy's default emphasis on one's own profile, career, and work, digital scholarship necessarily does not rest on the shoulders of a Primary Investigator. It emerges instead from the work of cross-departmental collectives of practice: teams, working groups, unconferences, nascent institutes, and collaborative projects.

- Community is intentional. The communities we build pull others toward ideals of common, shared labor; of attribution and recognition of invisible work; of the greater moral good as the guiding spirit in discussions of contention. The communities we build run not only across disciplines, but also across hierarchies. Digital scholarship is people: associate professors, students, archivists, technical staff, directors, developers.

- Because digital scholarship is such a young discipline, its practitioners are given the freedom to remix existing methodologies, experiment with materials, and work across disciplinary boundaries. This flexibility allows and compels us to innovate in the face of outdated traditions and to bring people together to collaborate on the ongoing growth and development of new ideas and initiatives.

- Librarians have been engaged in community building far longer than digital scholarship has existed. Digital scholarship challenges us think about how our concepts of "community" are changing as new platforms, disciplinary groups, and scholarly landscapes shift. It is important for the library to act intentionally, bridging gaps between academics of all ranks, the public, and other potential community members.

\section{6. ...breaks down disciplinary silos}

- Those practicing digital scholarship come from myriad disciplinary backgrounds, enriching the foundation of digital scholarly praxis. As such, digital scholarship resists attempts to be corralled into any one field, thereby serving as a bridge across disciplinary divides. As a scholarly practice in and of itself which borrows and contributes methodologies and modes of inquiry from many academic corners, digital scholarship fights against the siloization of the academy, and serves as a model for dismantling the walls of the silos themselves.

- In order to promote greater flexibility, deeper collaboration, and increased innovation across campus, digital scholarship questions library service models 
that restrict communication between disciplinary scholars and the library to a single departmental liaison.

\section{7. ...advocates for sustainable labor models}

- Digital scholarship offers a model for resisting unequal work by centering the infrastructure, labor, and process of scholarship over/against pure productivity. As a rejection of labor valued by quantified neoliberal metrics, digital scholarship depends on processes and policies that allow researchers to invest time in long-term projects and sustainable work.

- Digital scholarship, therefore, advocates for, encourages, and relies on time to think: about stewardship of research data, about participation in monopolistic publication infrastructures, about resistance against/within technologies in the classroom, and about the need for public participation and engagement with intellectually rigorous outputs, and more.

- The library, with a long history of organizing and advocacy, should push for sustainable and ethical labor models centered on allowing people to produce knowledge under healthy and compassionate work systems. Developments that digital scholarship practitioners grapple with- new modes of scholarly publication, evaluating and compensating intellectual work-have exacerbated existing tensions in the landscape of labor within the academy. It is the role of all digital scholarship professionals (and indeed all library professionals) to engage with the realities of these new labor challenges in the academy.

\section{8. ....redefines the relationship between research and teaching}

- All good scholarship is attentive to the need for a meaningful relationship between research and teaching. However, through its commitment to openness, innovation, and leveraging the affordances of networked information technologies, digital scholarship seeks to redefine this relationship in a number of important ways.

- The rise of Open Educational Resource (OER)-enabled pedagogy provides an excellent example of this trend, particularly insofar as it recasts the role of students from passive consumers of information to active contributors to the scholarly record. This trend has been enabled by the growing prevalence of open licensing as means of maximizing information dissemination and combatting the excesses of the global intellectual property regime. Insofar as digital scholarship demands familiarity with open research practices and innovations in technical infrastructure, DS practitioners are ideally positioned to advance this new understanding of the relationship between research and teaching in the digital environment. 


\section{9. ....reorients the role of academy}

- As a champion of opening discourse around access to information, digital scholarship positions the library in a leadership role for questioning and reconciling the academy's/university's stated goals with community needs and interests.

- Restrictive access to personnel and resources reinforces the university as the sole point of knowledge sharing. The academy, as a whole, needs to address the tension between its current modes of praxis and its assumed mission as service to and betterment of its various communities, including the surrounding locally-situated public, policy and advocacy initiatives at regional or national levels, and the global scholarly community.

- Digital scholarship focuses on access to and dissemination of information and resources. Therefore, digital scholarship must also ask critical questions about the role of the academy in the community at large. DS provides a fertile ground and/or space for organizing across-between disciplines for discussing, experimenting with, and advancing the practices that promote these forms of engagement between the academy and the broader social sphere.

\section{0 ....is not a service}

- Libraries and librarians hold tightly to an ethic of service, for the betterment of our communities. That impulse should not cause us to minimize or downplay the impact of our research and scholarship. Library/rian expertise in areas of digital scholarship are not "services" but representations of our own scholarly work, intellectual labor, and professional and personal interests.

- Digital scholarship inherently complicates the service-based relationship that has often been prevalent in librarian/scholar interactions, because librarians' knowledge of infrastructure, access, and sustainability is more obvious in a digital scholarship environment. The library contains expertise that extends well beyond the ability to serve scholars' needs. In order to promote a more equitable model for publication, librarians from all corners of the library should assert their expertise within interactions with other members of the campus community.

\section{Conclusion and Next Steps}

Librarianship is in a constant state of flux, and we believe that the rise of digital scholarship heralds a seismic change in the landscape of library practice. DS will not remain on new, contested ground forever; it will eventually become more central to our shared professional practice. Currently, though, due to convergences of campus and national "open" policies, a preponderance of library technology infrastructures, a cadre of professionals who grew into this field alongside the shifts toward Openness in all its forms, and the interest/support from organizations like SPARC, CNI, ACRL, and ARL, this topic is at the fore and represents a 
unique opportunity for our work in our local contexts. These statements about what digital scholarship does are meant to serve as a point of discussion, a catalyst for adaptation, a provocation, and a rallying cry. Based entirely in our own experiences and hopes for digital scholarship, we expect that these precepts will produce a diversity of opinions and ideas that will make a stronger and better sense of this work.

In effort to press the advantage, our colleague Carolyn Moritz will release an annotated bibliography that informed many of our discussions throughout the writing process. The bibliography will serve as a supplemental research product, and should be taken in context with, and apart from, the claims embedded here. Finally, we will release, and are already compiling, a Taxonomy of Digital Scholarship Activities in Libraries (TaDiSAIL), forked from the foundational Taxonomy of Digital Research Activities in the Humanities (TaDiRAH). We hope this taxonomy will provide a lexicon for our colleagues to accurately describe their work to research partners, library and campus administrators, and in promotion and tenure binders. Together, this statement, the annotated bibliography, and TaDiSAIL form a theoretical foundation for how we conceptualize digital scholarship at Florida State University Libraries. 


\section{Brief Bibliography of Bold Statements}

Reproducing the Academy: Librarians and the Question of Service in the Digital

Humanities

Roxanne Shirazi

a skunk in the library

Bethany Nowviskie

In Service? A Further Provocation on Digital Humanities Research in Libraries

Trevor Muñoz

Planned obsolescence: Publishing, technology, and the future of the academy

Kathleen Fitzpatrick

Service +/- collaboration for digital humanities in the library (a DH job talk)

Amanda Visconti

New Model Scholarly Communication: Roadmap for Change

Abby Smith Rumsey

The Productive Unease of 21st-century Digital Scholarship

Julia Flanders

Trends in Digital Scholarship Centers

Joan Lippincott, Harriette Hemmasi and Vivian Lewis

For Slow Scholarship: A Feminist Politics of Resistance through Collective Action in the

Neoliberal University

Alison Mountz, Anne Bonds, Becky Mansfield, Jenna Loyd, Jennifer Hyndman, Margaret Walton-Roberts, Ranu Basu, Risa Whitson, Roberta Hawkins, Trina Hamilton, Winifred Curran 